\title{
Problematising international placements as a site of intercultural learning
}

\author{
Jonathan Parker, Sara Ashencaen Crabtree, Azlinda Azman, Dolly Paul Carlo, Clare \\ Cutler
}

\section{Pre publication copy}

Published online $13^{\text {th }}$ June 2014 Jonathan Parker, Sara Ashencaen Crabtree, Azlinda Azman, Dolly Paul Carlo \& Clare Cutler (2014): Problematising international placements as a site of intercultural learning, European Journal of Social Work, DOI: 10.1080/13691457.2014.925849

\begin{abstract}
This paper theorises some of the learning outcomes of a three-year project concerning student learning in international social work placements in Malaysia. The problematic issue of promoting cultural and intercultural competence through such placements is examined, where overlapping hegemonies are discussed in terms of isomorphism of social work models, that of the nation-State, together with those relating to professional values and knowledge; and the tyrannies of received ideas. A critical discussion of cultural competence as the rationale for international placements is discussed in terms of the development of the graduating social worker as a self-reflexive practitioner. The development of sustainable international partnerships able to support student placement; and the issue of non-symmetrical reciprocation, typical of wide socio-economic differentials across global regions, is additionally discussed.
\end{abstract}

Keywords: international placement, cultural competence, hegemony, self-reflexivity 


\section{Introduction}

This paper theorises some of the learning outcomes of a three-year British Council funded project ${ }^{\mathrm{i}}$ promoting UK student mobility to Malaysia. The funding served to support an evolving programme of international placements for social work students at Bournemouth University (BU), UK, in keeping with the University's strategic aim of the internationalisation of the curriculum.

Cultural and intercultural competence is an oft-promoted end within social work learning throughout the world but remains a contested area and multi-nuanced (Laird, 2008; Bartoli, 2013). It has attracted criticism for its tendency to homogenise cultures, behaviours and ethnic groups with calls made to develop anti-oppressive or anti-racist practice as alternatives. In this joint Malaysia-UK project we were seeking to foster awareness and appreciation of difference and diversity and to challenge preconceived notions of homogeneities of cultural differences from all quarters. We understood cultural competence to represent the ability to negotiate different cultures challenging one's assumptions and reflecting on the transferability of learning to other settings. We did not view cultural competence as a naïve attempt to homogenise or 'essentialise' stereotypical characteristics of different ethnic and cultural groups, and chose the term for its positive emphases on human understanding, as opposed to the more potentially reactive approaches enshrined within some approaches to anti-oppressive and anti-racist practice.

\section{Background to the study}

Optional international placements at BU, commencing in 2009, were an innovation for this particular social work degree programme, and were therefore largely experimental. Over time the number of days offered increased from a 20-working-day placement in Malaysia, to 25 